\title{
INCREASING PRECISION OF BATCH PIPE FORMING METHOD USING BURRING AND IRONING OF LARGE DIAMETER STEEL PIPE IN FEM ANALYSIS
}

\author{
TATSUHIRO ONIZUKA ${ }^{*}$, KYOHEI OGAWA ${ }^{*}$ AND SHINICHI NISHIDA \\ * Graduate School of Science and Technology \\ Gunma University \\ 29-1, Honcho, Ota City, Gunma, 373-0057, Japan \\ e-mail: snishida@gunma-u.ac.jp
}

Key words: Burring, Ironing, SGP pipe, Compression test, FEM analysis.

\begin{abstract}
This paper describes increasing precision of Batch Pipe Forming Method Using Burring and Ironing of Large Diameter Steel Pipe in FEM Analysis. Branch pipes are one of the components of the piping system in a factory that serves as a flow path for gases and fluids. The bifurcated tube is formed by burring as a typical molding technique. The burring process is to form a branch pipe by raising the peripheral portion of the prepared hole formed in the mother pipe. There is a problem that the cutting of the edge is required in the post process. Therefore, a branch pipe batch forming method has been developed in which burring processing that does not require a cutting step in the subsequent step is combined with ironing processing using FEM analysis. The purpose of this research is to improve the accuracy of FEM analysis in the branch pipe batch forming method using burring process and ironing process by cutting the material into a cylindrical shape and performing a compression test to obtain the deformation resistance of the actual material. The experimental results were compared with the analytical results and approximately good agreement was obtained.
\end{abstract}

\section{REFERENCES}

[1] Okada, K., et al. Analysis of deformation behaviour in burring of tube using temperature gradient. Journal of the Japan Society for Technology of Plasticity. (1991) 32 (364): 583588.

[2] Teramae, T., et al. Optimum Forming Conditions for Incremental Tube Burring with a Bar Tool Using FE Simulation. Journal of the Japan Society for Technology of Plasticity. (2009) 50 (581): 560-564.

[3] Teramae, T., et al. Effect of material properties on deformation behavior in incremental tube-burring process using a bar tool. Journal of Material Processing Technology. (2007) 191 (1-3): 24-29.

[4] Yang, C., et al. Dieless incremental hole-flanging of thin-walled tube for producing branched tubing. Journal of Materials Processing Technology. (2014) 214 (11): 24612467.

[5] Alves, L.M., et al. Tube branching by asymmetric compression beading. Journal of Materials Processing Technology. (2012) 212 (5): 1200-1208.

[6] Ishikawa T. Current status and trends of numerical simulation of metal forming. Journal of Japan Institute of Lite Metals. (2009) 59 (7): 365-370.

[7] Ishikawa T. Prediction of Ductile Fracture in Cold Forging. Journal of Japan Society for Technology of Plasticity. (2012) 53 (620): 790-794. 